\title{
Usefulness of Soil $p$-Nitrophenyl Acetate Esterase Activity as a Tool to Monitor Biodegradation of Polybutylene Succinate (PBS) in Cultivated Soil
}

\author{
Yasuo SAKAI, ${ }^{*, * *}$ Mari IsoKaWA, ${ }^{* *}$ Takashi MASUdA, ${ }^{* * *}$ Hisashi YoshioKa, ${ }^{* * * *}$ \\ Masahito HAYATSU, ${ }^{* *}$ and Koichi HAYANO** \\ *United Graduate School of Agricultural Sciences, Gifu University, 1-1 Yanagido, Gifu 501-1193, Japan \\ ${ }^{* *}$ Faculty of Agriculture, Shizuoka University, 836 Ohya, Shizuoka 422-8529, Japan \\ ${ }^{* * *}$ National Institute of Advanced Industrial Science and Technology, \\ 1-1-1 Higashi, Tsukuba, Ibaraki 305-8561, Japan \\ ${ }^{* * * *}$ Institute for Environmental Sciences, University of Shizuoka, 52-1 Yada, Shizuoka 422-8526, Japan
}

(Received May 13, 2002; Accepted August 27, 2002)

\begin{abstract}
Degradation behaviors of polybutylene succinate (PBS) and $p$-nitrophenyl acetate ( $p$ NPA) esterase activity in soil were monitored for six months in the experimental field located at Fujieda in Japan. The PBS used in this experiment was an aliphatic polyester which was under trial product as a new thermoplastic material $\left(M_{\mathrm{n}} \fallingdotseq 7.0 \times 10 .^{4}\right.$ This PBS was prepared through direct dehydration polycondensation without diisocyanate as coupling agent for increasing molecular weight. Cellulose filter paper was used as a control for the degradation test. This PBS strips $(50 \mathrm{~mm} \times 30 \mathrm{~mm}$, thickness of $0.3 \mathrm{~mm}$ ) mixed with field moist soil sample which had been sieved $(<2 \mathrm{~mm}$ mesh) were packed in bags made of glass-fiber filter papers. The bags were buried in the surface soil layer $(0-10 \mathrm{~cm})$ of experimental field. Weight of PBS strip was decreased by approximately $20 \%$ in six months. Scanning electron microscopy (SEM) photographs showed that the surface of the PBS strip was gradually corroded in soil. During PBS degradation, $p$ NPA esterase activity in the peripheral soil was higher than that of the soil without PBS addition. Actinomycetous PBS degrader was isolated from peripheral soil of degrading PBS strip using PBS agar plate. The isolate exhibited $p$ NPA esterase activity which was competitively inhibited by PBS particles. These results suggested that $p$ NPA esterase activity of soil is an useful indicator of PBS biodegradation in soil.

KEY WORDS Polybutylene Succinate (PBS) / Biodegradable Plastic / Soil Microorganisms / Soil

Esterase / Polybutylene Succinate (PBS) Degrading Microorganism /
\end{abstract}

Recently, the production of synthetic polymers mainly used as plastic products has been steadily increasing, resulting in the production of enormous quantities of wastes, causing a new type of environmental pollution due to the resistance of synthetic polymers to biodegradation. ${ }^{1,2}$ Most of the synthetic polymers are resistant to biodegradation while some of them can be biodegraded with relative ease. Some aliphatic polyesters belong to the latter category are the focus of much interest due to their biodegradability. Up to now, a number of chemically synthesized aliphatic polyesters have been commercialized. Polybutylene succinate (PBS) (Figure 1), copolymer of polybutylene succinate and adipate (PBSA), poly ( $\varepsilon$-caprolactone) (PCL) and polylactic acid (PLA) are common group of biodegradable aliphatic polyesters. ${ }^{3-5}$ Among them, PBS with higher melting point is attracted recently. BIONOLLE produced from Showa High-polymer Co. (Tokyo) is one of PBS polymer, which is synthesized through polycondensation in the presence of small amount of diisocyanate as chain extending agent. On the other hand, the PBS used in this study is prepared through direct dehydration by polyconden-

$$
\left[\mathrm{O}-\mathrm{CH}_{2}-\mathrm{CH}_{2}-\mathrm{CH}_{2}-\mathrm{CH}_{2}-\mathrm{O}-\mathrm{C}_{\mathrm{O}}-\mathrm{CH}_{2}-\mathrm{CH}_{2}-\mathrm{C}-\mathrm{O}\right]_{n}
$$

Figure 1. Chemical structure of polybutylene succinate (PBS) used in this study.

sation method using Ti/phosphoric acid catalyst. ${ }^{6-8}$ The difference between PBS used in this study and BIONOLLE is that PBS used in this study does not contain diisocyanate unit in its polyester chain. By the addition of phosphoric acid as catalyst, the PBS polyesters bearing number-average molecular weight $\left(M_{\mathrm{n}}\right)$ higher than $7.0 \times 10^{4}$ were synthesized within considerably short polycondensation times.

Until now, several information about PBS (BIONOLLE) degradation in soil has been presented. ${ }^{9,10}$ However, insufficient information was obtained about the degradation in soil of PBS used in this study under trial product. Furthermore, we consider that participation of soil enzymes related to the degradation of PBS in soil is indispensable. Field study of the biodegradability of this PBS polymer before use in practical application is needed. To understand the intensity of biological activity related to the degradation 
is important for estimation of the effect of the inputs on soil environment. Enzyme activity in soil is known to be useful indicator in soil which had been received various inputs. ${ }^{11,12}$ Because, soil enzymes are the catalysts of important metabolic process related to the decomposition of organic inputs including artificial organic substance in soil. There is litter information on the potential of soil enzymes as indicators of the effects of PBS addition on soils.

In this study, we examined whether biodegradation of PBS in soil raises the level of soil esterase activity, and tried to isolate PBS degrader from peripheral soil of degrading PBS strip using PBS agar plate. Then, we examined relationship between degradability of PBS and activity of esterase in peripheral soil of PBS strips, and tried to evaluate the effect of biodegradation of PBS on microbial population in soil.

\section{EXPERIMENTAL}

\section{Syntheses of PBS}

PBS used here was polymerized with a catalyst under trial products. ${ }^{6-8}$ This PBS was produced without using the molecular combination agent which is used currently in general. The synthesis of PBS was carried out at $240^{\circ} \mathrm{C}$. In the synthesis of the PBS oligomer, $20 \mathrm{~g}$ of succinic acid (SA) was added into a $100 \mathrm{~mL}$ three-necked flask with 1,4-butandiol (1,4-BG) according to the predetermined 1,4-BG/SA molar ratios $(1.1: 1.0)$. In the synthesis of PBS polymer, titanium tetraisopropoxide $\left(0.12 \mathrm{mmol} \mathrm{L}^{-1}\right)$ was added to the PBS oligomer as catalyst in the presence of phosphoric acid $\left(0.04 \mathrm{mmol} \mathrm{L}^{-1}\right)$. The polycondensation was conducted under a final degree of vacuum about 0.5 Torr. The purification was not conducted after a synthesis of oligomer and polymer PBS.

\section{Physical Characterization of PBS}

Molecular weight of the synthesized PBS was measured at $40^{\circ} \mathrm{C}$ by a Tosoh HLC-8020 GPC instrument. Chloroform was used as the eluent at a flow rate of

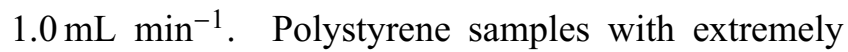
narrow molecular distributions were applied as standards to generate a calibration curve.

Measurements of Differential scanning calorimetry (DSC) and Thermogravimetry/Differential thermal analysis (TG/DTA) were implemented by a SEIKO SSC 5200 instrument. This synthesized polyester sample was firstly heated from -80 to $200^{\circ} \mathrm{C}$, then cooled to $-100^{\circ} \mathrm{C}$ at a scanning rate of $10^{\circ} \mathrm{C} \mathrm{min}^{-1}$. Melting point $\left(T_{\mathrm{m}}\right)$, heat of fusion $\left(\Delta H_{\mathrm{m}}\right)$ and glass transition temperatures $\left(T_{\mathrm{g}}\right)$ were estimated from the recorded DSC traces, respectively. TG/DTA measurements were carried out from ambient temperature to $500{ }^{\circ} \mathrm{C}$ at a heating rate of $10^{\circ} \mathrm{C} \mathrm{min}^{-1}$ under nitrogen atmosphere

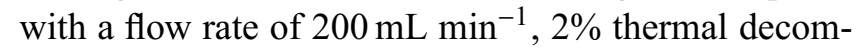
position temperature $T_{\mathrm{d}}(2 \%)$ were thus calculated.

The polymer PBS strips were prepared using a twinscrew extruder equipped with T-die and the thickness was nearly $0.2-0.3 \mathrm{~mm}$. Extrusion temperature was at $150^{\circ} \mathrm{C}$.

\section{Field Experiment}

Degradation test of the PBS strips were carried out for six months at the experimental field annexed to Shizuoka University in Fujieda. The soil samples used in this study were collected from topsoil in the experimental field, and passed through a 2-mm mesh screen (Antholosol; total $\mathrm{C}=1.00 \%$, total $\mathrm{N}=0.104 \%, \mathrm{pH}$ $\left.\left(\mathrm{H}_{2} \mathrm{O}\right)=5.72\right)$. The PBS and cellulose samples were mixed with soil and packed in bags made of glassfiber filter paper (ADVANTEC GA55, with a diameter of $150 \mathrm{~mm}) .{ }^{13}$ Two strips of PBS $(50 \mathrm{~mm} \times 30 \mathrm{~mm}$ in area, 0.50 to $0.70 \mathrm{~g}$ in weight) and two strips of cellulose $(50 \mathrm{~mm} \times 30 \mathrm{~mm}$ in area, 0.20 to $0.22 \mathrm{~g}$ in weight $)$ were put into each bag and buried in the surface soil of each field $(0-10 \mathrm{~cm})$ (Figure 2). Duplicate bags were sampled for every one month. The PBS strips in the bags were collected and washed with distillated water. Then the dry weight of PBS strips was measured. And observation on the surface of PBS strips was carried out using Scanning electron microscopy (SEM). SEM photographs were taken on a Hitachi S-2500 instrument operating at $20 \mathrm{kV}$ after sputtering with platinumpalladium ( $\mathrm{Pt}-\mathrm{Pd})$.

\section{Peripheral Soil Samples}

The peripheral soil of the collected strips was brushed down with brush and used for various analyses. In cellulose plot after July, soil samples around carbonized cellulose strip were collected as peripheral soil. The total carbon and the nitrogen content of the soil were determined by SUMIGRAPH (NC-900: SUMIKA Chemical analysis service).

\section{Soil Enzyme Assay}

Esterase. Esterase activity in soil was determined using $p$-nitrophenyl acetate ( $p$ NPA) (Sigma Co.) as substrate. Moist soil samples $(0.5 \mathrm{~g})$ were treated with $0.1 \mathrm{~mL}$ toluene and incubated with ester substrate ( $2 \mathrm{mmol} \mathrm{L}^{-1} p \mathrm{NPA}$ ) in $0.6 \mathrm{~mL}$ Tris (hydroxymethyl) aminomethane-maleic buffer $\left(0.5 \mathrm{~mol} \mathrm{~L}^{-1}, \mathrm{pH} 6.0\right)$ at $30^{\circ} \mathrm{C}$ for $0.5 \mathrm{~h}$. After the incubation, the contents were filtered and $p$-nitrophenol was estimated according to the method of Isokawa et al. ${ }^{14}$

Cellulase. Cellulase activity in soil was assayed by 


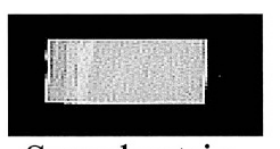

Sample strip

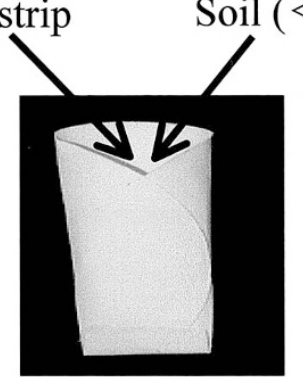

Glass fiber filter paper

(Packed in the bag)
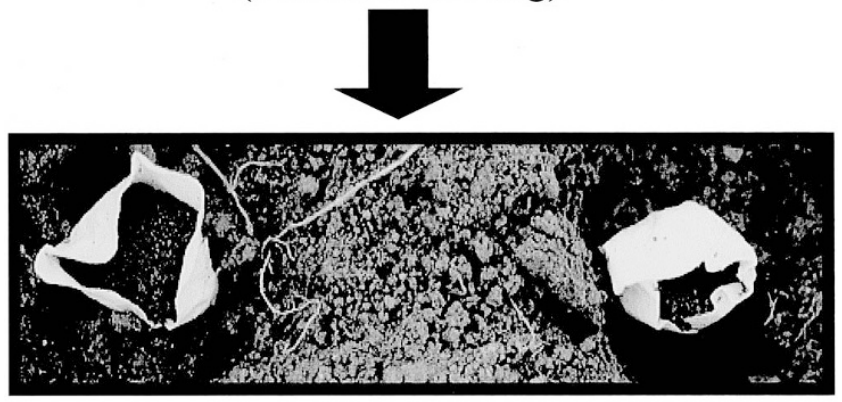

Buried in the field soil of samples

Figure 2. Burying method of PBS strips in the field soil.

the method of Kanazawa et al., ${ }^{15}$ using $p$-nitrophenyl $\beta$-D-cellobioside (Sigma Co.) as substrate. Moist soil samples $(0.5 \mathrm{~g})$ were treated with $0.1 \mathrm{~mL}$ toluene and incubated with cellulose substrate $\left(2 \mathrm{mmol} \mathrm{L}^{-1} p\right.$ nitrophenyl $\beta$-D-cellobioside) in $1.5 \mathrm{~mL}$ acetate buffer $\left(0.1 \mathrm{~mol} \mathrm{~L}^{-1}, \mathrm{pH} 5.0\right)$, at $30^{\circ} \mathrm{C}$ for $3 \mathrm{~h}$. After the reaction, the contents were filtered and $p$-nitrophenol was determined by the method of Hayano. ${ }^{16}$

Protease. Protease activity in soil was determined as described by Ladd and Butler ${ }^{17}$ with modifications suggested by Hayano. ${ }^{18}$ Moist soil samples $(0.5 \mathrm{~g})$ were treated with $0.1 \mathrm{~mL}$ toluene and incubated with peptide substrate $\left(10 \mathrm{mmol} \mathrm{L}^{-1} Z\right.$-phenylalanyl leucine (ZFL)) in $1.8 \mathrm{~mL}$ Tris borate buffer $\left(0.1 \mathrm{~mol} \mathrm{~L}^{-1}, \mathrm{pH} 8.1\right)$ for $1 \mathrm{~h}$ at $30^{\circ} \mathrm{C}$. The contents were filtered and amino acid released was determined by the method of Ladd and Butler. $^{17}$

The net activity of the all enzyme assays were determined after subtracting the values of two controls, either without soil or without substrate, and were expressed as $n$ mol of $p$-nitrophenol or L-leucine equivalents released per gram dry weight of soil per min $(\mathrm{mU}$ $\left.\mathrm{g}^{-1}\right)$. One unit of enzyme was defined as amount that releases $1 \mu \mathrm{mol}$ of $p$-nitrophenol or L-leucine per min at $30^{\circ} \mathrm{C}$.
Isolation of PBS-degrader from Peripheral Soil of Degrading PBS Strip

Agar plates of basal medium containing $2000 \mathrm{mg}$ $\mathrm{L}^{-1}$ emulsified PBS oligomer $(100 \mu \mathrm{m}$ average dia.) or PBS polymer $(300 \mu \mathrm{m}$ average dia.) particles were prepared according to Tansengco and Tokiwa (1998). ${ }^{3}$ $2000 \mathrm{mg}$ PBS sample was dissolved in $40 \mathrm{~mL}$ methylene chloride. The solution was emulsified by a homogenizer (10000 rpm for $5 \mathrm{~min}$ ), the content was added into the basal medium that composed of the following: $100 \mathrm{mg} \mathrm{L}^{-1}$ yeast extract, $1000 \mathrm{mg} \mathrm{L}^{-1}\left(\mathrm{NH}_{4}\right)_{2} \mathrm{SO}_{4}$, $200 \mathrm{mg} \mathrm{L}^{-1} \mathrm{MgSO}_{4} \cdot 7 \mathrm{H}_{2} \mathrm{O}, 100 \mathrm{mg} \mathrm{L}^{-1} \mathrm{NaCl}, 20 \mathrm{mg}$ $\mathrm{L}^{-1} \mathrm{CaCl}_{2} \cdot 2 \mathrm{H}_{2} \mathrm{O}, 10 \mathrm{mg} \mathrm{L}^{-1} \mathrm{FeSO}_{4} \cdot 7 \mathrm{H}_{2} \mathrm{O}, 1 \mathrm{mg} \mathrm{L}^{-1}$ $\mathrm{Na}_{2} \mathrm{MoO}_{4} \cdot 2 \mathrm{H}_{2} \mathrm{O}, 0.5 \mathrm{mg} \mathrm{L}^{-1} \mathrm{MnSO}_{4}, 1600 \mathrm{mg} \mathrm{L}^{-1}$ $\mathrm{K}_{2} \mathrm{HPO}_{4}$ and $200 \mathrm{mg} \mathrm{L}^{-1} \mathrm{KH}_{2} \mathrm{PO}_{4}$. After evaporation of methylene chloride from the medium by using a rotary evaporator at $50^{\circ} \mathrm{C}$ for $20 \mathrm{~min}, 12000 \mathrm{mg}$ agar was added to 1 liter of the emulsified medium ( $\mathrm{pH} 7.2)$, which was then sterilized in an autoclave for $20 \mathrm{~min}$ at $1 \mathrm{~kg} \mathrm{~cm}^{-2}\left(121^{\circ} \mathrm{C}\right)$.

YG agar medium used for purification of the isolates was composed of $180 \mathrm{mg} \mathrm{L}^{-1} \mathrm{~K}_{2} \mathrm{HPO}_{4}, 300 \mathrm{mg}$ $\mathrm{L}^{-1} \mathrm{KH}_{2} \mathrm{PO}_{4}, 180 \mathrm{mg} \mathrm{L}^{-1} \mathrm{MgSO}_{4} \cdot 7 \mathrm{H}_{2} \mathrm{O}, 1000 \mathrm{mg}$ $\mathrm{L}^{-1}$ yeast extract, $1000 \mathrm{mg} \mathrm{L}^{-1}$ glucose $(\mathrm{pH} \mathrm{7.0)}$ and $10000 \mathrm{mg} \mathrm{L}^{-1}$ agar.

Peripheral soil samples collected from PBS strips were diluted from $10^{3}$ to $10^{6}$ fold with sterilized water. An $1.0 \mathrm{~mL}$ of the suspension was inoculated on basal agar plate containing emulsified PBS oligomer. The agar plates were incubated at $30^{\circ} \mathrm{C}$ for 10 days. One colony with a distinct clear zone on the PBS oligomer agar plate was isolated and purified several times using the basal and YG agar medium. Finally, the pure culture of the PBS-degrader was confirmed with a distinct clear zone on the PBS agar plate.

\section{Extraction of pNPA Esterase from Clear Zone of PBS Agar Plate}

The basal medium containing PBS oligomer was poured into Petri dish (diameter, $90 \mathrm{~mm}$ ). The isolate of the PBS-degrader was inoculated and then incubated at $30^{\circ} \mathrm{C}$ for 3 days. After incubation, the agar around the colony with distinct clear zone was cut off to $50 \mathrm{~mL}$ beaker. A $12 \mathrm{~mL}$ phosphate buffer $(0.1 \mathrm{~mol}$ $\mathrm{L}^{-1}, \mathrm{pH}$ 7.0) was added into the beaker in which the agar piece was contained, and the enzyme of the PBSdegrader was extracted at $30^{\circ} \mathrm{C}$ for $1 \mathrm{~h}$ under agitation (160 rpm). The content was centrifuged at $27000 \mathrm{~g}$ for $15 \mathrm{~min}\left(4^{\circ} \mathrm{C}\right)$. After centrifugation, the supernatant was obtained as the crude enzyme extract. 
PBS Particles as an Inhibition Toward Actinomycete pNPA Esterase Activity

The enzyme extract obtained from the PBS agar plate with the clear zone $(0.2 \mathrm{~mL})$ was incubated with $2 \mathrm{mmol} \mathrm{L}^{-1} p$ NPA substrate in $0.2 \mathrm{~mL}$ Tris (hydroxymethyl) aminomethane-maleic buffer $\left(0.5 \mathrm{~mol} \mathrm{~L}^{-1}\right.$, $\mathrm{pH}$ 6.0) at $30^{\circ} \mathrm{C}$ for $1 \mathrm{~h}$ in absence or presence of $5000 \mathrm{ppm}$ PBS particles (100 $\mu \mathrm{m}$ average dia.). $2.4 \mathrm{~mL}$ ethanol was added to the reaction mixtures. After the incubation, the contents were filtered and $p$-nitrophenol was estimated according to the method of Isokawa et al. with $0.6 \mathrm{~mL}$ Tris (hydroxymethyl) aminomethane solution $\left(2 \mathrm{~mol} \mathrm{~L}^{-1}\right) .^{14}$

\section{Microbial Counts in Soil}

Colony forming units of bacteria, actinomycetes and fungi in soil were estimated by dilution plate methods, with an albumin agar, ${ }^{19}$ a Rose bengal agar ${ }^{20}$ respectively.

\section{RESULTS AND DISCUSSION}

\section{The Property of PBS Polyester}

The number-average molecular weight $\left(M_{\mathrm{n}}\right)$ of the PBS used in this study was about $4.0 \times 10^{3}$ (oligomer) and $7.0 \times 10^{4}$ (polymer), respectively. The PBS of polymer sample synthesized in the presence of phosphoric acid exhibited a melting point at $118^{\circ} \mathrm{C}$ and a similar glass transition temperature at $-37^{\circ} \mathrm{C}$. Moreover, the results of heat of fusion $\Delta H_{\mathrm{m}}=74 \mathrm{~J} \mathrm{~g}^{-1}$. On the other hand, result of TG/DTA analysis reveals PBS of polymer bear $2 \%$ thermal decomposition temperature at $310^{\circ} \mathrm{C}$.
The Relationship between PBS-degradation and Soil Enzyme Activities

Field experiment was carried out from May to November. The average soil temperature of this experimental term was $25.4{ }^{\circ} \mathrm{C}$. Cellulose strips in the soil degraded completely within about two months while degradation rate of PBS strip in soil was about 3\% per month (Figure 3). Figure 4 shows that the PBS strips were gradually degraded in visible state from the surface and retained its original form. Furthermore, surface of the PBS strips was morphologically observed by SEM. Progress of the biodegradation term in the soil, corrosion part and many minute holes were widely observed on the surface of the PBS strip as shown in Figure 5. From these results, it is thought that PBS strip is gradually corroded from the surface in soil. As the result, the weight of PBS strip decreased in soil.

The PBS has the ester bond in the chemical structure. Therefore, participation of the soil esterase as an enzyme which corroded on the surface of PBS strip was considered. Then, we collected the peripheral soil of each PBS strips and measured soil esterase activity using the artificial substrate ( $p$ NPA). Figure 6 shows the value of esterase, cellulase and protease activities in peripheral soil of PBS strips. Esterase activity was higher in peripheral soils of PBS strips than those of cellulose strips and no treatment soil. Results suggest that PBS-degrading microbes had accumulated in PBS plot. On the other side, cellulase activity was higher in peripheral soils of cellulose strips than in those of PBS strips. Protease activity assayed with ZFL was

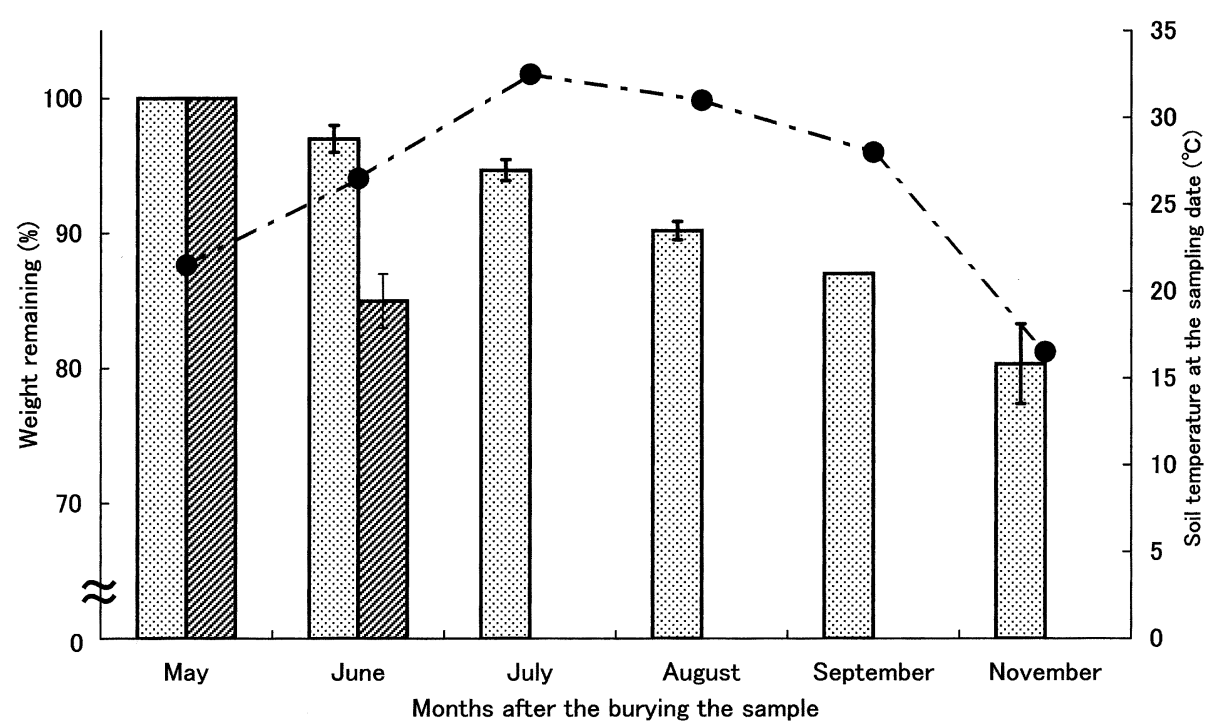

Figure 3. Changes of weight loss of PBS strips and soil temperature during degradation of PBS in soil. Samples were buried at the end of May. Degradation of the PBS (圈) and Cellulose (國) in the field from May to November. Each symbol shows the mean value of duplicate sample, and the bars show the standard deviation. The soil temperature was measured at every sampling time (•). 


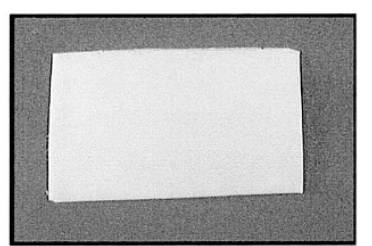

[Before burying]

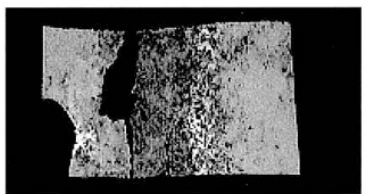

[6 months]
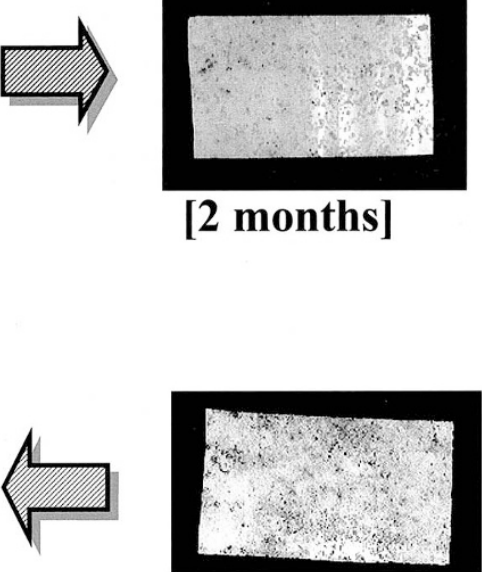

[4 months]

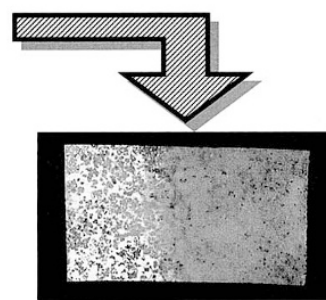

[3 months]

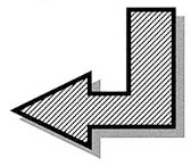

$50 \mathrm{~mm}$

Figure 4. The gradual degradation of PBS strips in the field during six months.

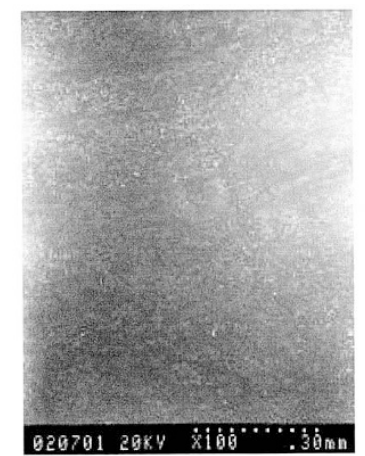

\section{[Before buring]}

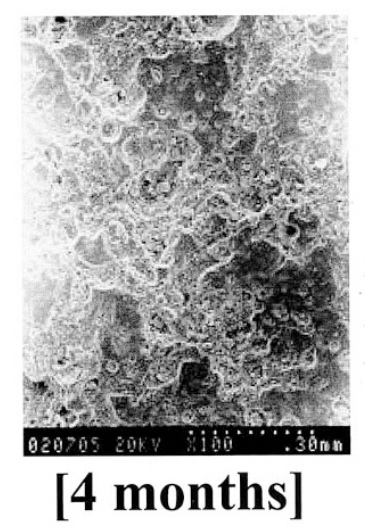

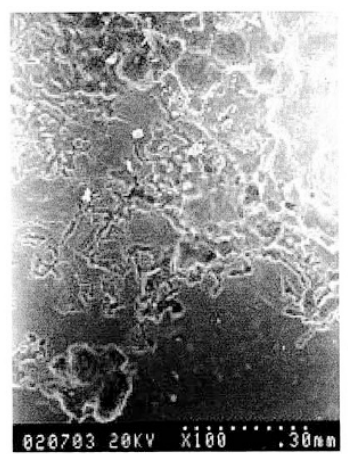
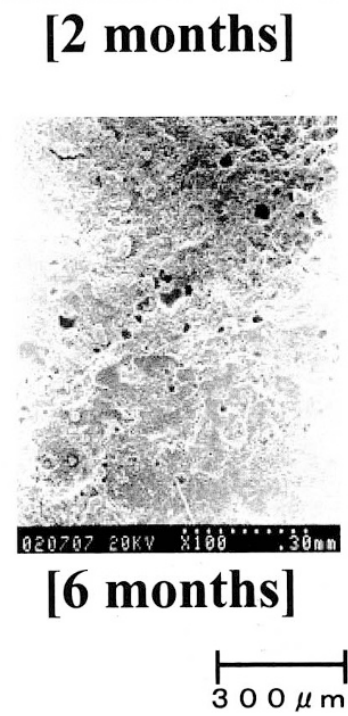

Figure 5. SEM photomicrographs on the surface of PBS strip buried in the field soil during six months $(20 \mathrm{kV}, \times 100$ fold $)$.

observed no difference among both peripheral soils of PBS and cellulose strips and no treatment soil. The results suggest that degradation of PBS in the soil was not based on the esterase activity which was originated from chymotrypsin type protease. ${ }^{21}$ Furthermore, the results show that the esterase activity which was detected with $p$ NPA as the substrate would be useful in-
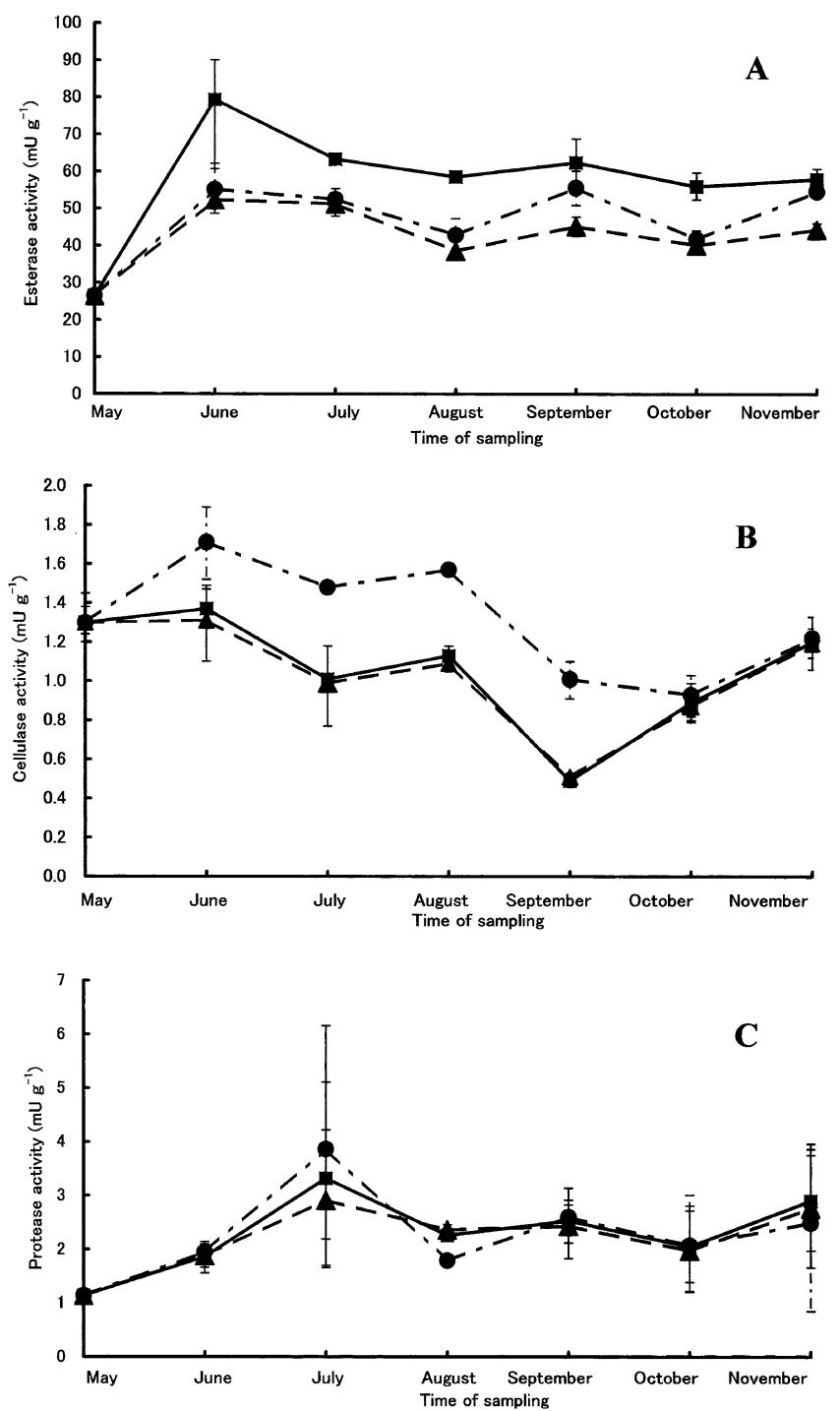

Figure 6. Changes of the esterase (A), cellulase (B), and protease (C) activities in peripheral soils of PBS strips ( $\mathbf{\square})$, cellulose strips ( $\bullet$, and no treatment soil $(\mathbf{\Lambda})$ in grass-fiber paper bags. The bars show the standard deviation. 


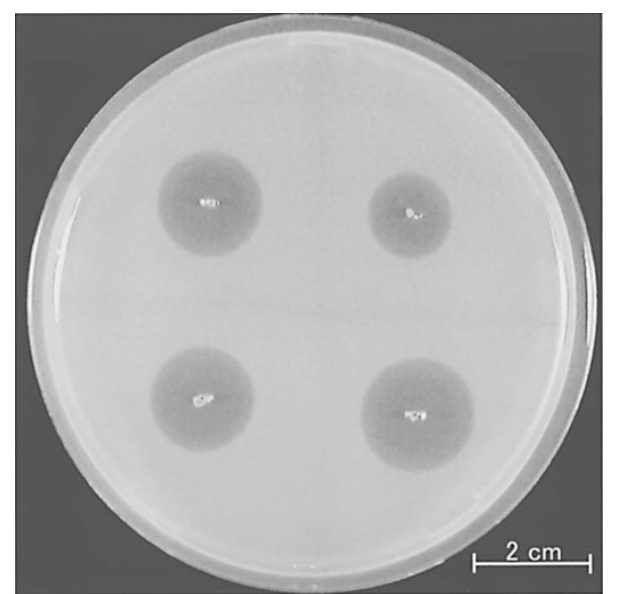

Figure 7. Colonies with clear zone of PBS degrader (FF-302) on an agar plate with emulsified PBS oligomer $\left(M_{\mathrm{n}} \fallingdotseq 4.0 \times 10^{3}\right)$.

dicator of the degradation of PBS in soil. Tokiwa et $a l^{22-24}$ reported that the lipase of Rizopus group has catalyzed the degradation of aliphatic polyesters.

Although this substrate ( $p$ NPA) was known to be hydrolyzed by carbonic anhydrase, ${ }^{25}$ chymotrypsin, ${ }^{21}$ and lipase, ${ }^{26}$ participation of aliphatic polyester degrading enzyme such as carboxyl esterase and lipase to the biodegradation of PBS in soil was considered. Present result in Figure 6 showed that hydrolysis of $p$ NPA in peripheral soil of PBS strips was responded to the degradation of the PBS polyester.

\section{Isolation of PBS-degrader in Soil}

A strain of PBS-degrader was isolated from peripheral soil of PBS strips. It was confirmed that the isolate formed clear zone on both oligomer and polymer PBS agar plates. The PBS oligomer agar plate has confirmed the clear zone from 7 to 10 days. On the other hand, the PBS polymer agar plate has confirmed the clear zone from 30 to 40 days. By using PBS of oligomer, PBS-degrader could be obtained efficiently and quickly from peripheral soil of PBS strips. We purified PBS degrader with YG agar medium. Microscopic observation revealed that strain FF-302 is likely to be an actinomycete. The population of actinomycetous PBS-degrader (FF-302) isolated from peripheral soil of PBS strips was approximately $10^{4} \mathrm{cfu} \mathrm{g}^{-1}$. A photograph of strain FF-302 colonies with clear zones on PBS oligomer agar plate is shown in Figure 7. Taxonomic identification of the strain is now in progress.

\section{PBS as an Inhibitor Towards pNPA Esterase from an Actinomycetous Isolate}

$p$ NPA esterase activity was detected in the extract from the clear zone around the colony of the isolate grown on PBS agar plate. Addition of PBS to the reaction mixture brought about the inhibition of the

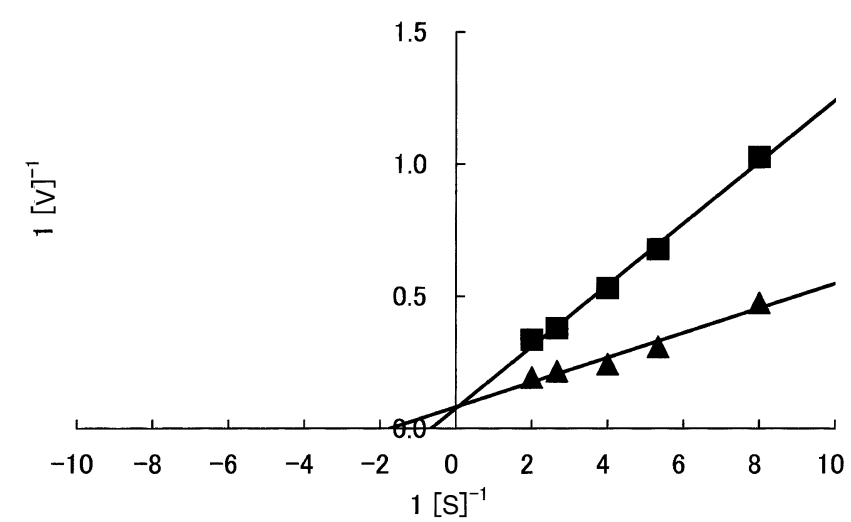

Figure 8. Competitive inhibition by PBS particles on hydrolysis of $p$ NPA. Ordinate $\left(1[\mathrm{~V}]^{-1}\right)$, reciprocal of $p$ NPA esterase activity; abscissa $\left(1[\mathrm{~S}]^{-1}\right)$, reciprocal of $p$ NPA concentration. $\mathbf{\Lambda}:$ no complexant, $\mathbf{a}$ : PBS particles added.

esterase activity. The Lineweaver-Burk plot obtained with $p$ NPA esterase activity in absence or presence of PBS particles was shown in Figure 8. Assuming a Michaelis mechanism for competition between substrate and complexant, the competitive inhibition can be expressed as:

$$
\frac{1}{V_{\mathrm{i}}}=\frac{1}{V_{\max }}\left(K_{\mathrm{m}}+\frac{K_{\mathrm{m}} \cdot I}{K_{\mathrm{i}}}\right) \frac{1}{S}+\frac{1}{V_{\max }}
$$

where $I$ is the concentration of the complexant, $S$ is the substrate concentration, $K_{\mathrm{i}}$ and $K_{\mathrm{m}}$ was the dissociation constant, and $V_{\mathrm{i}}$ is the initial velocity in the presence of the complexant. In the mechanism, two straight lines of the reciprocal plots of $V$ and $S$, and $V_{\mathrm{i}}$ and $S$ should cross on a positive non-zero y-intercept. If two kinds of ester-substrate have been present together in a reaction mixture, one should work as a competitive inhibitor of the hydrolysis of another, and vice versa. Figure 8 shows $p$ NPA hydrolysis was inhibited by PBS in a competitive fashion. This inhibition implies that the enzyme has absorbed to solid PBS surface. In degradation of the solid substrate, it has been known that the degrading enzyme adsorbs to the substrate. ${ }^{27}$ Recently, Mukai et $a l .{ }^{28}$ reported that the enzymatic degradation on the surface of poly hydroxyalkanoate (PHA) film by the PHA depolymerase, takes place via a two step mechanism; adsorption and hydrolysis. The first step consists of adsorbing the enzyme on the surface of PHA film via the binding domain, and the second step is hydrolysis of the polymer chain by the catalytic site. Results in Figure 8 suggest that $p$ NPA is a potential substrate for detection of PBS degrading activity and the part of the $p$ NPA esterase activity is related to the PBS degradation.

\section{Microbial Counts in Peripheral soil of PBS Strip}

Figure 9 shows that the populations of fungi $\left(10^{5}-\right.$ $\left.10^{6} \mathrm{cfu} \mathrm{g}^{-1}\right)$, bacteria $\left(10^{7} \mathrm{cfu} \mathrm{g}^{-1}\right)$ and actinomycetes 

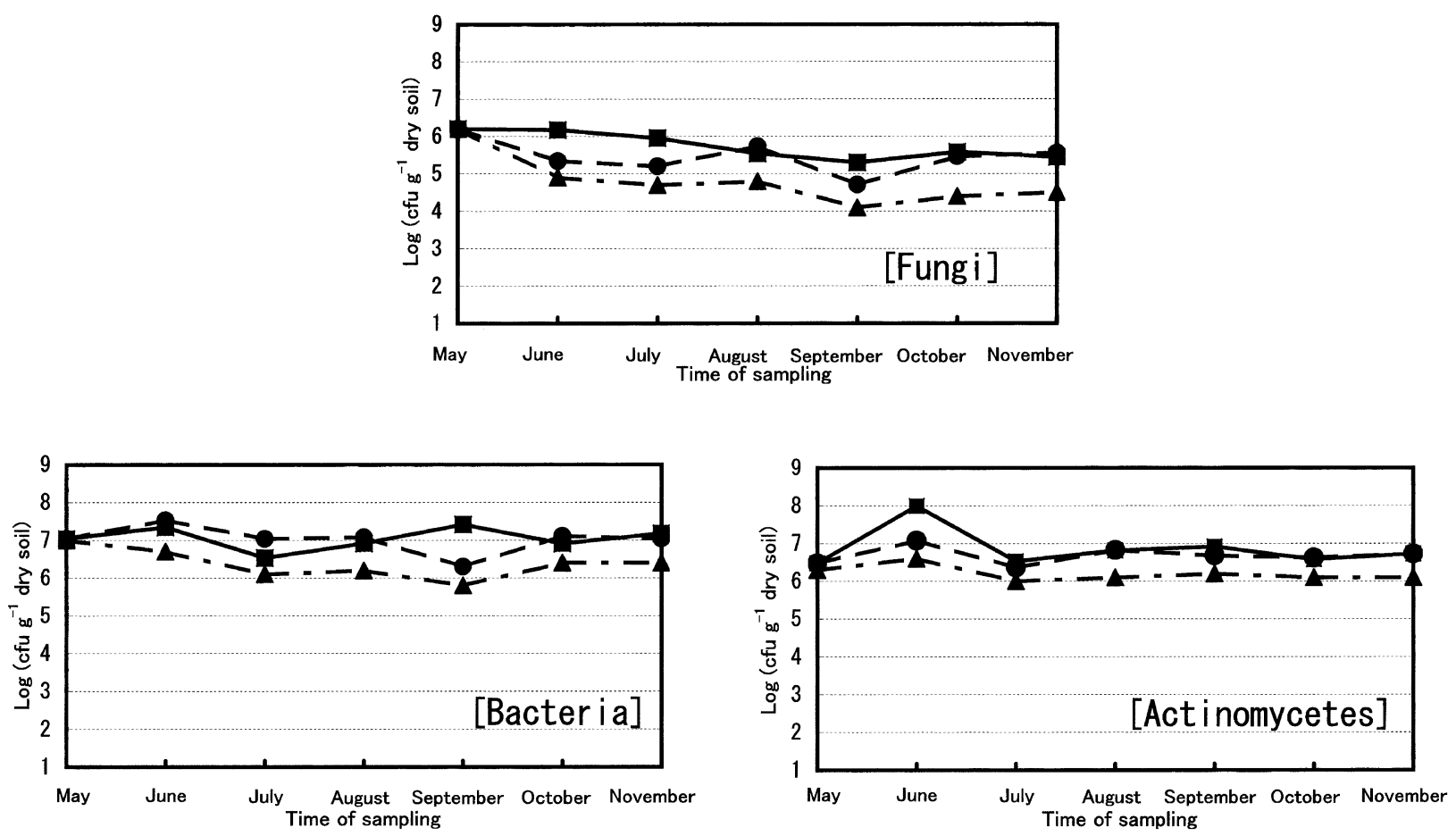

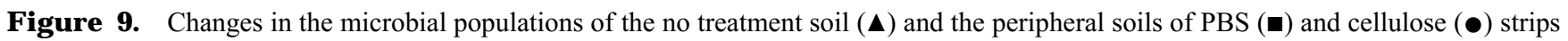
buried in the field from May to November.

$\left(10^{7} \mathrm{cfu} \mathrm{g}^{-1}\right)$ in the peripheral soil of PBS strips were not fluctuated significantly during six months. The populations of fungi, bacteria and actinomycetes in the peripheral soil of PBS and cellulose plot were higher than those of no treatment soil plot. No significant difference was observed in microbial population in soil between PBS and cellulose except for population of bacteria in September and actinomycetes in Jun. In these cases, the significant differences in cfu were often observed into peripheral soil between PBS and cellulose strip. At present time, we have no explanation for the discrepancy between them. However, it was observed that the populations of fungi, bacteria and actinomycetes in the peripheral soil of PBS plot were similar to or higher than those of cellulose plot. These results might suggest that PBS and the degradation products in soil were used similarly to cellulose as energy source for soil microorganisms.

\section{CONCLUSION}

From the results presented here, it can be concluded that this PBS under trial product are degraded about $3 \%$ per month in cultivated soil. From the result of SEM observation, decrease of this PBS weight was considered owing to the corrosion on the surface by PBS-degrading enzyme in soil. During degradation of PBS, the value of esterase activity became higher in peripheral soils of PBS strips than that in those of cellulose strips and no treatment soil. Furthermore, an acti- nomycetous PBS-degrader (FF-302) was isolated from peripheral soil of PBS strips. $p$ NPA esterase extracted from the PBS-degrader was affinitive to PBS particles; suggesting that existence of PBS-degrader similar to FF-302 strain raised the level of the esterase activity in the peripheral soil of PBS strips. These results lead us to the conclusion that $p$ NPA esterase activity of soil may be an useful indicator of PBS biodegradation in soil.

\section{REFERENCES}

1. O. Hrabak, FEMS Microbiol. Rev., 103, 251 (1992).

2. S. Y. Lee, Biotech. Bioeng., 49, 1 (1995).

3. M. L. Tansengco and Y. Tokiwa, Chem. Lett., 1043 (1998).

4. T. Suyama, Y. Tokiwa, P. Ouichanpagdee, T. Kanagawa, and Y. Kamagata, Appl. Envi. Microbiol., 64, 5008 (1998).

5. H. Pranamuda, Y. Tokiwa, and H. Tanaka, Appl. Environ. Microbiol., 61, 1828 (1995).

6. I. Takahashi, K. Koumoto, A. Matsuda, and T. Masuda, "Biodegradable Plastics and Polymers", Elsevier Science Publishers B.V., Amsterdam, 1994, vol. 4, p 596.

7. Y. He, T. Masuda, A. Cao, N. Yoshie, Y. Doi, and Y. Inoue, Polym. J., 31, 184 (1999).

8. T. Masuda, A. Cao, and K. Nakayama, Japanese Patent 3073985 (Jan. 2, 2000).

9. H. Nishide, K. Toyota, and M. Kimura, Soil Sci. Plant Nutr., 45, 963 (1999).

10. A. Hoshino, H. Sawada, M. Yokota, M. Tsuji, K. Fukuda, and M. Kimura, Soil Sci. Plant Nutr., 47, 35 (2001).

11. R. Yamada and H. Okino, Aichi-ken Nogyo Sogo Shikenjo Kenkyu Senta Hokoku., 21, 273 (1989). 
12. K. Ohashi and S. Yoshida, Soil Sci. Plant Nutr., 34, 293 (1988).

13. K. Maeda and Y. Onikura, Nippon Dojo Hiryo Kagaku Zasshi., 48, 567 (1977).

14. M. Isokawa, Y. Sakai, M. Hayatsu, and K. Hayano, Nippon Dojo Hiryo Kagaku Zasshi., 73, 45 (2002).

15. S. Kanazawa, K. Mori, M. Hiroki, and S. Matsumoto, Kankyo Kagaku Kaishi., 6, 251 (1993).

16. K. Hayano, Soil Sci. Plant Nutr., 19, 103 (1973).

17. J. N. Ladd and J. A. Butler, Soil Biol. Biochem., 4, 19 (1972).

18. K. Hayano, Nippon Dojo Hiryo Kagaku Zasshi., 49, 158 (1978).

19. S. A. Waksman and E. B. Fred, Soil Sci., 14, 27 (1922).

20. J. P. Martin, Soil Sci., 69, 215 (1950).
21. P. Desnulle, "The Enzymes" 3rd ed, Academic Press, New York and London, 1972, vol. 7, pp 575-616.

22. Y. Tokiwa and T. Suzuki, Agric. Biol. Chem., 42, 1071 (1978).

23. Y. Tokiwa and T. Suzuki, J. Appl. Polym. Sci., 26, 441 (1981).

24. Y. Tokiwa, T. Suzuki, and K. Takeda, Agric. Biol. Chem., 50, 1323 (1986).

25. G. P. Hess, "The Enzymes" 3rd ed., Academic Press, New York and London, 1971, vol. 3, pp 213-248.

26. S. Lindskog and P. D. Boyer, "The Enzymes" 3rd ed., Academic Press, New York and London, 1971, vol. 5, pp 587645.

27. A. D. McLaren and L. Packer, Adv. Enzymol., 33, 245 (1970).

28. K. Mukai, K. Yamada, and Y. Doi, Int. J. Biol. Macromol., 15, 361 (1993). 